\title{
De kredietcrisis: het failliet van risk management?
}

\section{Fred de Koning}

SAMENVATTING Ondanks alle ontwikkelingen op het gebied van kwantitatief risk management, die de laatste jaren hebben plaatsgevonden (mede gestimuleerd door Basel II), heeft de financiële wereld de kredietcrisis ${ }^{1}$ niet kunnen vermijden.

In dit artikel wordt onderzocht waarom risk management niet heeft kunnen betekenen wat wij daarvan verwacht hadden en welke lessen daaruit getrokken kunnen worden.

\section{RELEVANTIE VOOR DE PRAKTIJK Van gemaakte fouten moet men leren. Alom was er} een onbeperkt vertrouwen in kwantitatieve modellen voor de beheersing van financiële risico's. De kredietcrisis heeft dit vertrouwen danig geschokt. Het is zinvol na te gaan wat nog bruikbaar is van het gedachtegoed op het gebied van risk management en hoe risk management beter ingepast kan worden in de gangbare theorieën op het gebied van interne beheersing en management control.

\footnotetext{
1 Inleiding

Leenaars (2003) wees er enkele jaren geleden al op dat de toepassing van risicomanagement bij banken sterk was toegenomen. Toch heeft dit de kredietcrisis niet kunnen voorkomen. Misschien heeft het de kredietcrisis juist gestimuleerd. In ieder geval is duidelijk geworden dat de nodige vraagtekens gezet moeten worden bij kwantitatieve vormen van risk management ter beheersing van kredietrisico's. In paragraaf 2 van dit artikel wordt aan de hand van een analyse van de kredietcrisis onderzocht waarom het risk management gefaald heeft ten aanzien van de risico's die aan subprime leningen verbonden waren. Daarbij wordt onder meer ingegaan op de door Nassim Taleb (2001) beschreven inherente zwakte van de kansberekening, die aan modellen voor kwantitatief risk management ten grondslag ligt.

In paragraaf 3 wordt ingegaan op de vraag of een meer holistische benadering van risk management, zoals onder meer in COSO ERM (2004) wordt bepleit, een oplossing zou kunnen bieden. De conclusie is dat de holistische benadering de inherente zwaktes van het kwantitatief risicomanagement niet oplost en bovendien weer andere
}

problemen oproept. In paragraaf 4 wordt het risk management tegenover de traditionele benadering van interne beheersing en management control gesteld, waarbij wordt geconcludeerd dat risk management deze traditionele benaderingen niet kan vervangen, hoogstens kan aanvullen. In paragraaf 5 wordt het betoog samengevat en wordt benadrukt dat bij de beheersing van bedrijfsprocessen de nadruk moet komen te liggen op transparantie, waarvoor doelgerichte en betrouwbare informatie noodzakelijk is.

\section{De rol van risk management bij de kredietcrisis}

De belangrijkste oorzaak van de kredietcrisis is de securitisatie van subprime hypotheken, dat wil zeggen het financieren van hypothecaire leningen door middel van obligaties met de verstrekte hypotheken als onderpand. Dit is enigszins vergelijkbaar is met de pandbrieven, die vroeger in Nederland werden uitgegeven. In de Verenigde Staten worden dergelijke leningen 'Collateralized Debt Obligations' (CDOs) of 'Mortgage Backed Securities' genoemd. Op zich is securitisatie geen probleem. Het biedt een oplossing voor het financieringsprobleem van grote hypotheekverstrekkers, zoals de semi-overheidsinstellingen Fannie Mae en Freddy Mac in de Verenigde Staten, die als taak hebben ook minder kredietwaardige personen te helpen bij de financiering van een huis. Het probleem zit vooral in de verdeling van een te financieren pool van hypothecaire leningen in zogenaamde tranches, waarbij de 'beste' tranches - doorgaans versterkt door subordinatie ${ }^{2}$ van de andere tranches en toerekening van de 'excess spread' 3 - van de credit rating agencies ${ }^{4}$ hoge ratings kregen, met name AAA-ratings. De slechtere tranches, met uiteraard lagere ratings, kwamen vaak bij hedgefunds terecht (Wray, 2008). Bij het functioneren van de credit agencies in het kader van de kredietcrisis zijn overigens wel meer vraagtekens te plaatsen, onder meer op het gebied van belangenverstrengeling en (gebrek aan) toezicht (Boot, 2008a).

Banken hanteren tegenwoordig kwantitatieve modellen 
voor het bepalen van het kredietrisico. Het gaat daarbij vooral om het statistisch bepalen van de kans op kredietverliezen (defaultkansen). Die kans kan worden afgeleid uit tabellen van rating agencies (Leenaars, 2003). Basel II stelt de kapitaalvereisten voor banken afhankelijk van de risico's die aan hun activa zijn verbonden. Bij securitisaties schrijft Basel II het gebruik van credit ratings voor als basis voor het bepalen van het kredietrisico. Slechts wanneer er voor bepaalde producten geen ratings voorhanden zijn, mag het kredietrisico met eigen methoden worden bepaald (Basel Committee on Banking Supervision, 2004). Credit ratings spelen dus een belangrijke rol bij het bepalen van het kredietrisico van banken. De ratings zijn gebaseerd op statistische analyses van historische gegevens en inschattingen van risico's door de rating agencies en hebben daardoor duidelijk hun beperkingen.

Volgens Whalen (2008) is er sprake van een overdreven vertrouwen in kwantitatieve methoden die gebruikmaken van historische marktgegevens. Over de markt van innovatieve financiële producten zijn nog onvoldoende historische gegevens beschikbaar. De inherente risico's van financiële instellingen, die innovatieve producten ontwikkelen en op de markt brengen, zijn daarbij over het hoofd gezien. Neal (2008) wijst erop dat de modellen zijn gebaseerd op de aanname dat de financiële structuur van de economie ongewijzigd blijft, zelfs wanneer de economie wordt overspoeld met steeds riskantere financiële instrumenten, die er mede op zijn gericht goed uit deze modellen naar voren te komen. Zij houden geen rekening met liquiditeitsproblemen en een systeemcrisis, wellicht minder voor de hand liggende risico's, maar wel met ingrijpende gevolgen. Taleb heeft in zijn boek 'The Black Swan'(2007) beschreven, dat minder waarschijnlijke gebeurtenissen die een grote impact kunnen hebben vaak niet gezien worden. Zo werd het tot 1697 - het jaar waarin Willem de Vlaming in Australië voor het eerst zwarte zwanen zag - in de Westerse wereld voor onmogelijk gehouden dat er zwarte zwanen bestonden.

De opkomst van de securitisatie vond plaats in een periode van enorme groei van de leverage ratios van hedgefunds en investeringsbanken (Blundell-Wignall, 2008). Dit leidde tot een sterke toename van de geldhoeveelheid, waardoor behoefte ontstond aan goed renderende beleggingen met beperkt risico, dat wil zeggen een goede credit rating. Dat heeft de opkomst van de subprime lening versterkt, terwijl tegelijkertijd de instabiliteit van het wereldwijde financiële systeem toenam. De frequentieverdeling die aan kwantitatieve analyses ten grondslag ligt, is vaak scheef. Dat betekent dat er een grote kans is op een beperkte winst gecombineerd met een kleine kans op een groot verlies. Dat wordt wel de 'Taleb-verdeling' genoemd. Zo kunnen hedgefunds jarenlang een goed resultaat laten zien (en daar bonussen voor het management op baseren!) totdat het onwaarschijnlijke zich voordoet en de zaak onderuit gaat. In het geval van Long Term Capital Management was dat de val van de Roebel in 1998 (Dunbar, 2000). In het geval van Amaranth was het een onverwachte daling van de prijs van termijncontracten voor aardgas in een winterperiode (Morgenson en Anderson, 2006).

\section{Een holistische benadering van risico's?}

Sommige auteurs (Mikes, 2009; Andersen, 2008) suggereren een bredere, holistische benadering van risico's als oplossing voor de beperkingen van de kwantitatieve modellen om financiële risico's te bepalen. In deze paragraaf zullen wij nagaan of dat werkelijk een oplossing biedt.

Mikes (2009) onderkent voor banken vier vormen van (enterprise) risk management:

1) 'Risk silo management', gebaseerd op kwantificering van risico's in verschillende risicocategorieën, zoals marktrisico, kredietrisico, verzekerbaar risico en operationeel risico. Daarbij wordt gebruik gemaakt van overkoepelende technieken, zoals value at risk, en specifieke technieken voor het bepalen van het kredietrisico. De silobenadering' wordt volgens Mikes gestimuleerd door Basel II.

2) 'Integrated risk management', gebruikmakend van de techniek van economic (risk) capital, te definiëren als het statistisch bepaalde vermogen dat nodig is om alle verplichtingen op te kunnen vangen bij een negatief scenario. Deze benadering sluit aan op de manier waarop rating agencies hun credit ratings bepalen.

3) 'Risk based management', gericht op het optimaliseren van de aandeelhouderswaarde, waarbij technieken worden gebruikt als 'risk adjusted return on capital' (RAROC) en de toegevoegde aandeelhouderswaarde (economic profit). Een dergelijke benadering wordt volgens Mikes vooral gepropageerd door consultants en business schools.

4) 'Holistic risk management', waarbij alle risicocategorieën in ogenschouw worden genomen inclusief moeilijk te kwantificeren risico's, zoals strategische, operationele en compliance-risico's. Deze benadering tracht een invulling te geven aan corporate governance, waaraan vooral in Angelsaksische landen een grote waarde wordt toegekend. Bij de holistische benadering worden technieken gebruikt afkomstig uit de bedrijfskunde (zoals scenarioanalyse) of auditing (zoals risk self assessments).

Mikes heeft de toepassing van de laatste twee vormen van risicomanagement nader onderzocht bij twee banken en komt daarbij tot de conclusie, dat het risk based management een strategische dimensie aan het risicomanagement 
toevoegt door integratie met strategische planning en prestatiemanagement. Wat betreft interne beheersing ziet Mikes deze benadering vooral als diagnosticerend. De holistische benadering geeft het topmanagement meer inzicht in het proces van risk management, doordat daarbij verschillende bedrijfsprocessen in ogenschouw worden genomen. Dat zou een positief effect van deze vorm van risk management kunnen zijn. Holistisch risicomanagement heeft echter ook belangrijke nadelen, zoals wij in het navolgende zullen zien.

Andersen (2008) bepleit een 'total risk management', dat door hem wordt gedefinieerd als de vaardigheid om zodanig op alle exogene marktfactoren in te spelen dat de variabiliteit van resultaten wordt beperkt. Total risk management omvat volgens hem: beheersing van strategische risico's, operationele risico's, economische risico's en verzekerbare risico's. Andersen heeft jaarcijfers van 1386 Amerikaanse ondernemingen onderzocht en heeft daaruit de conclusie getrokken dat total risk management positief gecorreleerd is aan de gerealiseerde resultaten. Het total risk management wordt door hem bepaald als de standaarddeviatie van de omzet gedeeld door de standaarddeviatie van de resultaten, oftewel de mate waarin de onderneming in staat is de winst te stabiliseren bij een variabele omzet. Men kan zich echter afvragen of de stabilisatie van resultaten wel het gevolg is van het toepassen van risk management (in welke vorm dan ook). Bowman (1980) veronderstelde op basis van de economische theorie dat een ondernemer beloond wordt voor het lopen van risico's. Daaruit zou volgen dat een grotere spreiding in resultaten positief gecorreleerd moet zijn aan de hoogte van de resultaten. Zijn onderzoek leidde echter tot tegengestelde resultaten. Dat staat sindsdien bekend als de 'Bowman paradox'. Diverse auteurs hebben zich naderhand het hoofd gebroken over mogelijke verklaringen voor deze schijnbare paradox 5 . Andersen houdt het nu op goed risk management, maar weet dat onvoldoende te onderbouwen.

De holistische benadering wordt ook gepropageerd door COSO ERM (2004). Een kwantitatieve benadering van alle enterprise risks levert, zoals ook Mikes (2009) concludeert, in de praktijk de nodige problemen op. COSO ERM opent daarom de deur voor kwalitatieve vormen van risicoanalyse. Voor financiële risico's is dat echter geen optie. Financiële risico's worden door COSO ERM dan ook min of meer genegeerd, in ieder geval niet als afzonderlijke categorie risico's gezien. Het model is vooral gericht op strategische en operationele risico's, waaronder het compliancerisico en het rapporteringsrisico.

Uit een eerder door ons uitgevoerd onderzoek naar de praktijk van risicomanagement (De Koning, 2006) bleek dat banken meer dan andere bedrijfstakken gebruik maken van kwantitatieve methoden voor risk management, die vooral op financiële risico's zijn gericht. Zij waren daar (toentertijd!) ook meer dan gemiddeld tevreden over. COSO ERM bleek bij banken relatief weinig te worden toegepast. De conclusie moet dan ook zijn dat een holistische benadering geen oplossing biedt voor het gesignaleerde probleem, dat wil zeggen de in de vorige paragraaf beschreven beperkingen van de kwantitatieve modellen om met name financiële risico's te beheersen. Bovendien genereert een organisatiebrede, geïntegreerde benadering van risico's een coördinatieprobleem. Het hoogste management moet een belangrijk deel van het risk management delegeren naar lagere echelons in de organisatie. Het coördinatiemechanisme daarbij is het 'risk appetite'; de mate waarin risico's acceptabel zijn. Iedere vorm van risk management vraagt om enige mate van risk appetite. Anders zouden alle gesignaleerde risico's afgedekt moeten worden. Dan kan niet meer van ondernemen worden gesproken. Vooral bij een kwalitatieve benadering blijkt het lastig het risk appetite op een duidelijke manier te omschrijven. Echter, zonder een duidelijke en bruikbare aanduiding van de te accepteren risico's zullen managers op lagere niveaus in de organisatie terughoudend zijn in het accepteren van risico's. De neiging kan dan ontstaan de geconstateerde risico's zo veel mogelijk af te dekken, wat kan leiden tot een inefficiënte en ongewenste bureaucratisering. Zo maakt Hampton (2008) melding van een onderneming, die 2.900 risico's geïnventariseerd had en vervolgens probeerde de risico's in een geïntegreerd proces te beheersen. Volgens hem zien de meeste ondernemingen het nut van een dergelijke inspanning niet in. Hij is van mening dat het centraal beheren van duizenden bedrijfsrisico's weinig toevoegt. Ook andere auteurs melden problemen bij de uitvoering van COSO ERM (Richter Quinn, 2006; Williamson, 2007; Baker, 2008). Het wordt vaak als te complex en tijdrovend gezien.

\section{Interne beheersing versus risk management}

De vakgebieden interne beheersing en management control bestuderen al jaren de optimale inrichting van beheersingssystemen in organisaties. Daarbij wordt niet zozeer vanuit de risico's geredeneerd als wel vanuit de te beheersen processen. De handboeken op het gebied van interne beheersing besteden dan ook weinig tot geen aandacht aan risk management. Zie bijvoorbeeld Starreveld c.s. $(2002)^{6}$, Anthony en Govindarajan (2003) en Merchant en Van der Stede (2007). Ook Simons (1995) legt geen relatie tussen zijn vermaarde 'levers of control' en risk management.

Beheersingsmaatregelen kunnen grofweg ingedeeld worden in preventieve en repressieve ${ }^{7}$ (detectieve) maatregelen. Binnen het vakgebied management control wordt de laatste jaren veel aandacht besteed aan de laatste categorie in de vorm van performance management. Het handboek van Merchant en Van der Stede (2007) voert tegenwoordig zelfs de ondertitel: 'Performance measurement, evaluation 
and incentives', waarbij op typisch Amerikaanse wijze prestatiemeting meteen wordt doorgetrokken tot prestatiebeloning. ${ }^{8}$. Prestatiebeloning houdt overigens het gevaar in dat managers zich gaan richten op kortetermijnresultaten en bereid zijn daarbij veel risico te nemen. Dat neemt niet weg dat het meten van prestaties een effectieve vorm van interne beheersing is.

Het toepassen van risk management zal echter vaak leiden tot meer preventieve maatregelen. Het gaat er daarbij immers vooral om de kans op het zich voordoen van ongewenste gebeurtenissen zo veel mogelijk te beperken. Preventieve maatregelen omvatten functiescheiding, richtlijnen, procedures, budgetten, normen, et cetera. Deze maatregelen passen goed bij hiërarchisch-bureaucratische organisaties (De Koning, 2008). In organisaties met een andere cultuur of een ander coördinatiemechanisme bestaat het gevaar dat het nemen van veel preventieve maatregelen demotiverend gaat werken. Zo wijzen Frey en Jegen (2001) erop dat toezicht een negatief effect op de intrinsieke motivatie van medewerkers kan hebben.

Een minimumniveau van preventieve maatregelen is echter in de meeste organisaties wel gewenst. Denk bijvoorbeeld aan de beheersing van het betalingsverkeer. Het is echter de vraag of het nodig is risk management toe te passen om tot een goede set maatregelen te komen. In toenemende mate maken organisaties gebruik van ERPsystemen, die niet alleen een goede logistieke en administratieve ondersteuning aan bedrijfsprocessen kunnen bieden, maar ook beschikken over de nodige - op 'best practices' gebaseerde - beheersingsmaatregelen (Walker, 2008). Het belangrijkste daarbij is dat de uitgevoerde activiteiten juist en volledig in het geautomatiseerde systeem worden geregistreerd. Met andere woorden: de corporate database en het daaraan ten grondslag liggende datamodel moeten een goede weergave bieden van de bedrijfsprocessen (Koning, 2000). Doelgerichte en betrouwbare informatie over bedrijfsprocessen is de kern van een goede interne beheersing. Veel banken hadden miljardenafboekingen kunnen voorkomen als het management voldoende op de hoogte was geweest van de (analyse van) risico's, die aan subprime leningen verbonden waren. Het drama bij Société Générale (AFP, 2008) had voorkomen kunnen worden als tijdig duidelijk was geworden welke posities de handelaar Kerviel had ingenomen'. De megafraude bij Madoff Investments (Schwartz, 2008) had niet zo lang door kunnen woekeren als stakeholders (waaronder de SEC) betrouwbare informatie over de werkelijke gang van zaken hadden gekregen.

Intuïtief lijkt risk management een goede aanpak om daar een systeem van interne beheersing op te baseren. Interne beheersing omvat immers het nemen van maatregelen om risico's te beperken. Het lijkt dan ook voor de hand te liggen om eerst de risico's in kaart te brengen en daarna pas het systeem van interne beheersing op te zetten. Na de inventarisatie van risico's moet voor ieder relevant risico een oplossing gezocht worden. Dat kan leiden tot een lappendeken aan maatregelen. De vakgebieden interne beheersing en management control bevatten een schat aan kennis en ervaring ten aanzien van de beheersing van bedrijfsprocessen. Daarmee kunnen goed doordachte, conceptuele beheersingssystemen opgezet worden. In feite probeert men deze systemen opnieuw uit te vinden als de interne beheersing afhankelijk gesteld wordt van het uitvoeren van een risicoanalyse.

Risk management kan wél een zinvolle rol spelen als er sprake is van bijzondere risico's; van de standaard afwijkende bedrijfsprocessen en transacties, waarvoor de - al dan niet in ERP-systemen opgenomen - standaard beheersingsconcepten een onvoldoende oplossing bieden. Ook kan risk management uitgevoerd worden als "proof of the pudding' om vast te stellen dat het systeem van interne beheersing geïnventariseerde risico's in voldoende mate afdekt (De Koning, 2008).

\section{Samenvatting en conclusie}

Investeerders, bankiers en credit raters hebben teveel vertrouwd op kwantitatieve modellen voor risk management. Deze modellen steunen voor een belangrijk deel op historische gegevens. De toekomst kan anders uitpakken. De holistische benadering van bedrijfsrisico's, die vaak kwalitatief wordt uitgevoerd, kan dit probleem niet oplossen. Het leidt tot complexe en subjectieve analyses, waarmee de toekomst ook niet kan worden voorspeld. De essentie van een goede interne beheersing en management control is betrouwbare informatie. Kortom, informatie die een goed inzicht geeft in de (resultaten van) bedrijfsprocessen. Daar moet de aandacht vooral op gericht worden. Transparantie is dus het sleutelwoord.

Ook ten aanzien van het financial risk management is transparantie noodzakelijk. Hoe zitten de modellen in elkaar en op welke historische en andere gegevens zijn zij gebaseerd? Bennis et al. (2008) wijzen erop dat bij complexe besluitvormingsprocessen betere resultaten worden behaald, wanneer de informatie die aan de besluitvorming ten grondslag ligt, door meer betrokkenen wordt gedeeld. Moore en Brauneis (2008) zijn van mening dat een grotere transparantie en een verbeterd beheer van de kwantitatieve modellen de kloof tussen de 'kwantitatievelingen' en de bankiers zal verkleinen en zal helpen om tot een beter geïnformeerde besluitvorming te komen.

Bankiers en investeerders dienen weer interesse in hun business te krijgen en niet alleen voor het grote geld te gaan, waarbij zij de kern van hun functie (het managen van financiële risico's) aan specialisten over laten. Het stemt droevig wanneer uit de mond van een topbankier het volgende citaat kan worden opgetekend: 'We wisten niet 
beter dan dat het Amerikaanse AAA-hypotheekobligaties waren. We hebben geen onderzoek gedaan naar de onderliggende hypotheekportefeuilles. Het onderscheid tussen prime en subprime dat de markt nu maakt, zag ik toen niet' (De Horde en Zevenbergen, 2008).

De conclusie is dat doelgerichte en betrouwbare informatie de basis blijft voor een goede besluitvorming en een goede interne beheersing. Collega Boot (2008b) stelt dan ook terecht: 'Zo is in het huidige denken transpa- rantie cruciaal voor de ontwikkeling van financiële markten en is transparantie ook bijna een codewoord voor goede corporate governance.'

Prof. dr. W.F. de Koning RE RA is hoogleraar aan Business Universiteit Nyenrode en aldaar voorzitter van de vakgroep Bestuurlijke Informatieverzorging

\section{Literatuur}

AFP (2008), Kerviel had mogelijk handlanger binnen Société Générale, www.nrc.nl/economie/ article1901833.ece, gepubliceerd: 23 mei 2008 , gewijzigd: 31 juli 2008.

- Andersen, T.J. (2008), The Performance Relationship of Effective Risk Management: Exploring the Firm-Specific Investment Rationale, Long Range Planning, Volume 41, Issue 2, April, pp. 155-176.

- Anthony, R. en V. Govindarajan (2003), Management Control Systems, McGraw-Hill, Education - Europe, 11th Revised edition. - Baker, N. (2008), Real-world ERM, Internal Auditor, Vol. 65, Issue 6, pp. 32-37.

- Basel Committee on Banking Supervision (2004), Basel II: International Convergence of Capital Measurement and Capital Standards: a Revised Framework.

- Bennis, W., Goleman, D., O'Toole, J. en Ward Biederman, P. (2008), Transparency: How Leaders Create a Culture of Candor, JosseyBass, San Francisco, CA.

- Blundell-Wignall, A. (2008), Subprime crisis: A capital issue, OECD Observer, May/June, Issue 267, pp. 24-25.

Boot, A.W.A. (2008a), Credit ratingbureaus en de stabiliteit van de financiële sector, Maandblad voor Accountancy en Bedrijfseconomie, jg. 82, no. 5, mei, pp. 227-234.

- Boot, A.W.A. (2008b), Zonder historisch perspectief van crisis naar crisis, Maandblad voor Accountancy en Bedrijfseconomie, jg. 82, no. 6, juni, pp. 54-55.

- Bowman, E.H. (1980), A risk/return paradox for strategic management, Sloan Management Review, Vol. 21, no.3, pp. 27-31.

- COSO, Committee of Sponsoring Organizations of the Treadway Commission (2004), Enterprise Risk Management (ERM) Integrated Framework, www.coso.org.
Drummond, H. (2003), Did Nick Leeson have an accomplice? The role of information technology in the collapse of Barings Bank, Journal of Information Technology, June, Vol. 18, pp. 93-101. - Dunbar, N. (2000), Inventing Money: The story of Long-Term Capital Management and the legends behind it, New York, Wiley. - Frey, B.S. en R. Jegen (2001), Motivation Crowding Theory, Journal of Economic Surveys, Vol. 15 Issue 5, December, pp. 589-611. - Hampton, J.J. (2008), Insurance industry reaches major crossroads, Business Insurance, Vol. 42, Issue 40, pp. 24-25.

- Hofstede, G. (2004), Business Goals and Corporate Governance, Asia Pacific Business Review, Vol. 10, No. 3-4, Summer, pp.292-301. - Horde, C. de, en B. Zevenbergen (2008), 'Ik wist niet wat subprime was', www.accountant.nl/Accountant/Nieuws, 23 februari 2008.

- Koning, W.F. de (2000), Bestuurlijke informatieverzorging, in het bijzonder

Informatiecontrole..., Nyenrode University Press.

- Koning, W.F. de (2006), Ervaringen met methoden voor risk management, Grip op Risicomanagement, Nyenrode-NRC Handelsblad-Eiffel, pp.33-46.

- Koning, W.F. de (2008), Visies op interne beheersing, Maandblad voor Accountancy en Bedrijfseconomie, jg. 82, no. 4, april, pp. 170-177. - Leenaars, J.J.A. (2003), Risicomanagement van banken, Maandblad voor Accountancy en Bedrijfseconomie, jg. 77, no. 7/8, juli/augustus, pp. 340-347.

- Merchant, K.A. en W.A. Van Der Stede (2007), Management Control Systems, Financial Times, 2e druk, ISBN-13: 9780273708018.

- Mikes, A. (2009), Risk management and calculative cultures, Management Accounting Research, Vol. 20, No. 1, pp. 18-40.
Moore, M.A. en M.L. Brauneis (2008), U.S. Subprime Crisis: Risk Management's Next Steps, Bank Accounting \& Finance, Vol. 21, No. 3, April-May, pp. 21-48.

- Morgenson, G. en J. Anderson (2006), A Hedge Fund's Loss Rattles Nerves, The New York Times, September 19, 2006.

- Neal, P. (2008), The Subprime Mortgage Crisis: Lessons for Regulators, Policy, Vol. 24 Issue 2, pp. 19-25.

- Richter Quinn, L. (2006), COSO at a Crossroad, Strategic Finance, Vol. 88, no. 1, July, pp. 42-49. - Schwartz, N.D. (2008), European Banks Tally Losses Linked to Fraud, The New York Times, New York edition, December 17, p. B1.

- Simons, R. (1995), Control in an age of empowerment, Harvard Business Review, Vol. 73, no.2, March-April, pp. 80-88.

- Starreveld, R.W., O.C. van Leeuwen en H. van Nimwegen (2002), Bestuurlijke Informatieverzorging, Deel 1: Algemene Grondslagen, $5 \mathrm{e}$ editie, Stenfert Kroese, Groningen/Houten.

- Taleb, N.N. (2007), The Black Swan: The Impact of the Highly Improbable, Random House Publishing Group.

Walker, K.B. (2008), SOX, ERP, and BPM, Strategic Finance, Vol. 90, Issue 6, December, pp. 47-53.

- Whalen, Chr. (2008), An empirical approach to Basel II, Journal of Risk Management in Financial Institutions, Vol. 1 Issue 2, JanuaryMarch, pp. 133-145.

- Williamson, D. (2007), The COSO ERM framework: a critique from systems theory of management control, International Journal of Risk Assessment \& Management, Vol. 7 Issue 8, pp. 1089-1119.

-Wray, L. R. (2008), Lessons from the Subprime Meltdown, Challenge, Vol. 51 Issue 2, March-April, pp. 40-68. 


\section{Noten}

1 Met de kredietcrisis wordt bedoeld de crisis in de financiële wereld, die in 2007 is ontstaan toen bleek dat zogenaamde "subprime" leningen, d.w.z. waardepapieren die minder solide hypotheken als onderpand hebben, aanzienlijk minder waard waren dan wat op grond van de door credit raters daaraan toegekende ratings verwacht had mogen worden. Allengs is deze financiële crisis steeds verder doorgedrongen in het economisch leven, waardoor met name na het faillissement van de investeringsbank Lehman Brothers op 15 september 2008 in veel landen een economische recessie ontstond, die inmiddels (januari 2009) als ernstig wordt ingeschat. Zie onder meer: Financieel Dagblad, Nieuwsdossiers, Kredietcrisis, http://www.fd.nl/nieuws/ dossiers/467248/8295894/
2 Subordinatie: het achterstellen van lagere tranches bij de verdeling van opbrengsten (met name bij vrijwillige of gedwongen vervroegde aflossingen)

3 Excess spread: het verschil tussen de ontvangen rente uit de hypothecaire leningen en de uit te betalen rente op de obligatielening. 4 In casu: Standard \& Poor's Credit Market Services, Moody's Investors Service en Fitch Inc. $\boldsymbol{5}$ Vanuit de visie van Bowman (ondernemers worden beloond voor het nemen van risico's) is dit een paradox. Vanuit andere visies (bijvoorbeeld: het resultaat hangt vooral van de marktpositie van de onderneming) is dit een te verwachten uitkomst.

6 In de laatste druk van het werk van Starreveld (2002), dat 919 pagina's omvat, worden welgeteld zes pagina's aan risicomanagement besteed. $\mathbf{Z}$ 'waarbij het begrip repressief wordt gebruikt in de zin van "ter achterhaling" en niet "ter onderdrukking"', Starreveld (2003), p. 397. Detectief is wellicht een duidelijker aanduiding. Merchant en Van der Stede (2007) spreken in dit verband over 'result controls', Simons (1995) heeft het over het 'diagnostic control system' en Hofstede (1978) over 'cybernetic control'.

8 Typisch Amerikaans is de nadruk op het eigenbelang. Hofstede (2004) signaleert dat 'personal wealth' bij MBA-studenten in Nederland en Duitsland niet wordt genoemd als één van de zes belangrijkste bedrijfsdoelstellingen, terwijl het in de Verenigde Staten op de derde plaats staat. 9. Hetzelfde geldt overigens voor de Leeson-affaire bij de Barings Bank (Drummond, 2003). 